\title{
SOFTWARE AND COMPUTER INTEGRATED MANUFACTURING
}

NEW NIST PUBLICATION

January 1991

\section{Howard M. Bloom}

U.S. DEPARTMENT OF COMMERCE

National Instrtute of Standards

and Technology

Center for Manufacturing EnIneering

Factory Automation Systems Division

Galthersburg, MD 20899

U.S. DEPARTMENT OF COMMERCE

Robert A. Mosbacher, Secretary

NATIONAL INSTITUTE OF STANDARDS

AND TECHNOLOGY

John W. Lyons, Director 



\section{SOFTWARE AND COMPUTER INTEGRATED MANUFACTURING}

Howard M. Bloom

U.S. DEPARTMENT OF COMMERCE National instjtute of Standards and Technoiogy

Center for Manufacturing Engineering Factory Automation Systems Division Gaithersburg, MD 20899

November 1990

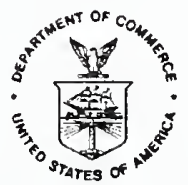

U.S. DEPARTMENT OF COMMERCE Robert A. Mosbacher, Secretary NATIONAL INSTITUTE OF STANDARDS AND TECHNOLOGY John W. Lyons, Dlrector 



\title{
Software and computer Integrated Manufacturing
}

\author{
Howard M. Bloom
}

Abstract. This paper outlines present and future directions for software in a computer Integrated Manufacturing (CIM) environment. The three major CIM components -- production management, data management, and communications management -- are described in terms of software available today and future software based on emerging international standards. Key standards efforts such as product data exchange, open systems interfaces, database systems frameworks, and CIM frameworks are described.

\section{Introduction}

Computer Integrated Manufacturing (CIM) is the integration of all the processes necessary to manufacture a product through the use of computer technology. In manufacturing, CIM is integration through the centralization of knowledge (Thompson and Graefe). In its fullest implementation, CIM integrates all manufacturing information, not just the manufacturing data for products, but also the business procedures, corporate goals, and management structure of a manufacturing enterprise.

Achieving an integrated manufacturing environment depends upon the design and implementation of a system architecture for CIM. Within this architecture computer software systems can be developed to drive the processes defined by CIM. The system architecture includes three separate but related architectures. These are production management, data management and communications (Jones, et al). Production management includes all of the functions related to the customer order, design, fabrication (e.g., machining), inspection, and customer support of products. Data management includes all functions related to the delivery of accurate and timely information to the production management processes. Communication management includes all functions required for the reliable transmission of messages among all of the computer systems in the enterprise.

This paper looks at the present state of software associated with the implementation of CIM architecture. Emphasis is placed on the need for the implementation of standards that will facilitate the integration of the software into a cost-effective CIM environment.

\section{Production Management Systems}

Production management systems can be divided into three major areas: manufacturing data preparation, shop-floor control, and administrative management. Manufacturing data preparation includes all the functions required to generate the data needed to manufacture a product capable of meeting a particular customer's requirements. Shop-floor control includes all the processes 
involved in manufacturing a particular product. Administrative management includes all the functions required to manage the overall enterprise, independent of any single product requirement.

Manufacturing data preparation software systems include computer Aided Design (CAD), Computer Aided Processing Planning (CAPP), and Computer Aided Manufacturing (CAM) systems. CAD systems are used to take user product requirements and generate product designs which include geometry data, tolerances, materials, and other required manufacturing specifications. CAPP systems can be used to take the output of a CAD system and generate a process plan, that is a complete list of raw materials, tools, machines, fixtures, and machining instructions to be used during the fabrication process. CAM systems starting with the output of the CAD system (and CAPP system) can be used to generate the Numerical Control (NC) code for machine tools. In some cases "CAM" can mean also the inspection code for coordinate measuring machines or the robot commands for controlling an industrial robot. For most CAM applications, the user must interact with the system in generating the final NC code for a given machine.

At the present time, there is a broad range of software products that provide capabilities usually as a function of the product type. The CAD system used for mechanical design is usually quite different than the system used for electronic design and relies on different analysis tools to generate an efficient product design. This is mainly due to the inherent 2-D nature of electronics and the 3-D nature of mechanical parts. CAPP systems are mostly interactive with the user participating in the generation of the plans. There are several programs presently available that employ "expert systems" that allow for the automatic generation of process plans, but these programs usually require an intensive initial effort to identify the rules that will be used for specific part families. Although CAD and CAPP systems were originally mainly available on mainframes, today they are almost exclusively implemented on either engineering work stations or personal computers (except in industries such as aerospace where large mainframes are a way of life).

Today's data preparation systems will be changing rapidly as the emerging standard, STEP (Standard for the Exchange of Product Model Data), becomes mature (Smith, et al). This standard will have the capability of defining all the information about a product needed for its entire life cycle. STEP will also specify the database environment in which the product data will be accessed. Finally STEP will have a set of "application protocols" which will specify both the information itself as well as how it is used for specific CIM applications.

Shop-floor control systems are usually hierarchical. One such system is a five level structure containing facility, shop, cell, workstation, and equipment (Bloom and McLean). The facility level 
performs the functions as defined for manufacturing data preparation and administrative management. The other four levels are responsible for driving the equipment on the shop floor based on the production schedule and products to be manufactured. At the present time there are many programs available for performing job scheduling and controlling the shop operations. However, there is not an effective link between shop-floor control and administrative management systems. This has resulted in the need to have software translators to convert the output of process planning systems and NC programming systems into the actual input used to drive the machines on the shop floor. Research efforts have been involved in developing a true "data driven" production environment, but this will ultimately require changes in the machine control architectures (as in the Next Generation Controller Project underway by the U.S. Air Force Manufacturing Technology Program.) In fact, future shop floor control systems will be driven by product data (e.g. STEP) that will eliminate the need for much of the intermediate software translations that are presently required (Bloom 89).

Administrative management systems include marketing information, sales/order processing, production program planning, purchasing, sales/dispatch, accounts payable, requirement planning, capacity management, material flow, cost accounting, payroll accounting, personnel information, accounts receivable, and financial accounting. These systems have been automated long before the manufacturing-related systems. The computer programs are usually developed for large mainframe computers (although today these systems are available on personal computers). They are often obtained as an integrated set from a single software vendor where the database integration comes with the programs. Historically there has been little interaction between the manufacturing software developers and the business systems developers. It is for this reason that CIM has been very difficult to implement (Fossum and Ettlie).

\section{Data Management}

There are two major issues related to data management: data modeling and data administration. Data modeling involves the development of a conceptual model of all the information involved in the CIM environment. There are several modeling techniques now available (as software products) that allow the representation of the real-world objects, as well as the information units that describe and distinguish them. An example of a public domain modeling technique is IDEF1, whichilias been used both in the manufacturing database environment, $1:$ well as in the standards community for STEP (IDEF1 1981). It is an extremely complex effort to integrate all the information used by CIM applications (Scheer), but a necessity, if an enterprise wants a successful CIM environment. 
The second data management issue, data administration, is the data services that control access to all data in an enterprise. This includes "query processing", "transaction management", and "data manipulation" (Jones, et al). There are many software database systems available today, some that allow only for a centralized access to shared data among the CIM processes and some that allow for a distributed access to the CIM data. Some of the database systems allow the applications that access the database to interact through a "data dictionary" which defines all the data and their interrelationships. In most cases, this means that the CIM database can be restructured without all the applications being revised.

The critical issue is how to integrate database systems from different vendors that are implemented on different computer platforms. This is the heterogeneous distributed systems environment that is the reality in the CIM world. An example of the system architecture required for implementing this environment is the Integrated Manufacturing Data Administration system (Libes and Barkmeyer).

Today's software systems are already making use of such standards as SQL (Standard Query Language), IRDS (Information Resource Dictionary system), and RDA (Remote Data Access) in order to offer complete data administration capability for CIM (Bloom, et. al. 1988). By using this open database architecture approach, the CIM application software vendors can produce software independent of the actual physical means of accessing the information that is required by the application.

\section{Communication Management}

The communications system provides the functions needed to transmit messages among computer programs executing production and data management tasks. There are three key concepts that facilitate effective CIM networks (Jones et al): (1) CIM programs use one common connection for communications with other programs, regardless of function or location, (2) physical networks are transparently interconnected, and (3) technology and topology of subnetworks are chosen to provide optimal communications responsiveness.

The communications software that is available today falls into two categories: closed system and open systems. The closed systems are those which rely only on products from a specific computer vendor. The open systems are those that adhere to the open systems Interconnection (OSI) network architecture (Weston et al). specific applications within the OSI framework include the Manufacturing Automation Protocols (MAP) concept of one physical bus connecting all factory-floor stations, and the Technical office Protocols (TOP) used for connecting engineering work stations. In particular, there is the Manufacturing Message Specification (MMS) 
Which provides the level of message handling support required at the specific device to be connected to the network.

\section{Standards Issues}

At the present time, implementing CIM in a company (or an enterprise that involves an industrial network of partners and subcontractors) requires a tremendous effort to develop software translators for the different applications and databases. If CIM is to be effective, internationally agreed-upon interface standards are necessary to avoid huge translation costs. The European Economic Community produced a Directory of European standardization Requirements for Advanced Manufacturing Technology (Directory 1990) that lists the required standards in terms of seven classifications:

Interworking covers the general framework for CIM architecture and communications (such as OSI).

Data covers the definition of information and related application data (such as STEP).

Processing covers the open systems framework for database systems and operating systems (such as IRDS).

Control Equipment covers the interfaces to manufacturing systems (such as NC controller codes).

Human Aspects covers the integration of human operators into a manufacturing environment.

Mechanical Aspects covers the standards needed for different classes of machines (such as turning centers).

General Aspects covers a set of methods of analysis and representation of enterprises.

Perhaps the most important standards activity at this time is the work by the International organization for standardization (ISO) Technical Committee on Industrial Automation (TC184) Subcommittee on Architecture and Communications (SC5) Working Group on CIM Architecture (WG1) on a framework for modeling CIM (ISO 1990). This work is based on the CIM-OSA (CIM Open Systems Architecture) project (ESPRIT 1989) which could revolutionize the development of CIM software systems.

\section{Conclusion}

CIM software systems of the future will be "plug compatible" with any system in an enterprise based on the emerging standards described in this paper. Applications will have standard interfaces to database systems through standard communication 
protocols. All applications will be able to exchange product data through the use of a standard product data exchange structure. Software systems will be written using programming languages that exist in a standard operating systems framework (such as POSIX, an emerging international standard based on UNIX) that allows for total portability of applications and data among computer systems.

Perhaps the most exciting effort under way is the increased use by companies of "concurrent engineering" methodologies (Winner). The research and development now proceeding in design theory and methodology will lead to new ways of integrating the processes that make up a part of the product's life cycle.

\section{References}

BLOOM, HOWARD, 1989, The role of the National Institute of Standards and Technology as it relates to product data driven engineering, NISTIR 89-4078, (National Institute of Standards and Technology, Gaithersburg, Maryland).

BLOOM, HOWARD, FURLANI, CITA, MITCHELL, MARY, TYLER, JOAN, and JEFFERSON, DAVID, 1988, Information resource dictionary system: an integraton mechanism for product data exchange specification, NISTIR 88-3862, (National Institute of standards and Technology, Gaithersburg, Maryland).

BLOOM, HOWARD and MCLEAN, CHARLES, 1985, standardization suggested by the Automated Manufacturing Research Facility (AMRF) -- A research testbed for the factory of the future, Automated Manufacturing, ASTM STP 862, Gardner, L. Ed., (American Society for Testing and Materials), 38-60.

Directory of European Standardization Requirements for Advanced Manufacturing Technology, 1990, prepared by Information Technology Advisory Expert Group on Advanced Manufacturing Technologies, Memorandum M-IT-04, (CEN/CENELEC and ETSI, Brussels, Belgium).

ESPRIT Consortium AMICE eds., 1989, Open systems architecture for CIM, (Springer-Verlag, Berlin, Germany).

FOSSUM, BARBARA, and ETTLIE, JOHN, 1990, The reconciliation of MIS and manufacturing for integrated manufacturing, Proceedings of CIMCON 90, Jones, A. Ed., (National Institute of standards and Technology, Gaithersburg, Maryland).

IDEF1 Information Modeling Manual, 1981, ICAM Program Office, WPAFB, Ohio 45433 .

ISO TC 184/SC 5, 1990, Report from CEN/CENELEC on the progress of their work on CIM architecture, N187, (National Electronics Manufacturers Association, Washington DC). 
JONES, ALBERT, BARKMEYER, EDWARD, and DAVIS, WAYNE, 1989, Issues in the design and implementation of a system architecture for computer integrated manufacturing, International Journal of Computer Integrated Manufacturing, 2, 65-76.

LIBES, DON, and BARKMEYER, ED, 1988, The integrated manufacturing data administration system (IMDAS) -- an overview, International Journal of Computer Integrated Manufacturing, 1, 44-49.

SCHEER, AUGUST-WILHELM, 1989, Enterprise-wide data modelling, (Springer-Verlag, Berlin, Germany).

SMITH, BRAD, and RINAUDOT, GAYLEN, 1988, Product data exchange specification, NISTIR 88-4004, (National Institute of standards and Technology, Gaithersburg, Maryland).

THOMPSON, VINCE, and GRAEFE, UDO, 1989, CIM -- a manufacturing paradigm, International Journal of Computer Integrated Manufacturing, 2, 290-297.

WESTON, R., GASCOINE, J., RUI, A., HODGSON, A., SUMPTER, C., and COUTTS, I., 1988, steps towards information integration in manufacturing, International Journal of Computer Integrated Manufacturing, 1, 140-153.

WINNER, ROBERT I., PENNELL, JAMES P., BERTRAND, HAROLD E., and SLUSARCZUK, MARKO M. G., 1988, The role of concurrent engineering in weapons system acquisition, IDA Report R-338, (Institute of Defense Analysis, Alexandria, Virginia). 



\begin{tabular}{|c|c|c|}
\hline \multirow[t]{3}{*}{$\begin{array}{l}\text { NIST-114A } \\
\text { (REV. 3-89) }\end{array}$} & \multirow{3}{*}{$\begin{array}{l}\text { U.S. DEPARTMENT OF COMMERCE } \\
\text { NATIONAL INSTITUTE OF STANDARDS AND TECHNOLOGY } \\
\text { BIBLIOGRAPHIC DATA SHEET }\end{array}$} & $\begin{array}{l}\text { 1. PUELCATION OA REPOART MUMBEA } \\
\text { NISTIR } 4468\end{array}$ \\
\hline & & 2. PEETFORMINO OROAMIZATION REPORT MUMQER \\
\hline & & $\begin{array}{l}\text { 3. PUBUCACATION DATE } \\
\text { NOVEMBER I } 990\end{array}$ \\
\hline
\end{tabular}

$$
\text { SoItware and Computer Integrated Manufacturing }
$$

5. AUTHOR(S)

$$
\text { Howard M. Bloom }
$$

6. PERFORMINO OROANIZATION (IF JOINT OR OTHER THAN NIST, SEE INSTRUCTIONS) U.S. OEPARTMENT OF COMMERCE NATIONAL INSTITUTE OF STANDARDS AND TECHNOLOGY QAITHERSBURG, MD 20899 7. CONTRACT/GRANT MUMEER 8. TYPE OF REPORT AND PERIOD COVERED

9. SPONSORINO OROAMIZATION MAME ANO COMPLETE ADORESS (STREET, CITY, STATE, ZIP)

10. SUPPLEMENTARY MOTES

DOCUMENT DESCRIBES A COMPUTER PROGRAM; SF.185, FIPS SOFTWARE SUMMARY, IS ATTACHED.

11. ABSTRACT (A 200-WORO OR LESS FACTUAL SUMMARY OF MOST SIGMIFICANT INFORMATION. IF DOCUMENT IMCLUDES SIGNIFICANT BIBUOOAAPHY OR UTERATURE SURVEY, MENTION IT HERE.)

This paper outlines present and future directions for software in a Computer Integrated Manufacturing (CIM) environment. The three major CIM components -- production management, data management, and communications management -- are described in terms of software available today and future software based on emerging international standards. Key standards efforts such as product data exchange, open systems interfaces, database systems frameworks, and CIM frameworks are described.

12. KEY WOROS (6 TO 12 ENTRIES; ALPHABETICAL ORDER; CAPITALZE ONL WPROPER MAMES; AND SEPARARE KEY WOROS OY SEMICOLONS) Computer Integrated Manufacturing (CIM), Distributed databases, Manufacturing data preparation, enterprise application software, factory communications, product data exchange.

\section{AVAILABIUTY}

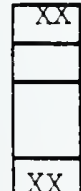

\section{UNUMITED}

FOR OfFICIAL DISTRIBUTION. DO NOT RELEASE TO NATIONAL TECHMICAL IMFORMATION SERVICE (NTIS).

ORDER FROM SUPERINTENDENT OF DOCUMENTS, U.S. GOVERMMENT PAINTING OFFICE, WASHINOTON, DC 20402

ORDER FROM HATIOMAL TECHMICAL INFORMATION SERVICE (NTIS), SPRIMGFIELD. VA 22161.
14. NUMBEA OF PRINTEO PAGES

$$
10
$$



